Article

\title{
Synthesis, Characterization and Tribological Evaluation of New Generation Materials for Aluminum Cold Rolling Oils
}

\author{
Ponnekanti Nagendramma *, Bal Mukund Shukla and Dilip Kumar Adhikari \\ Bio Fuels Division, CSIR-Indian Institute of Petroleum, Dehradun PIN-248005, India; shukla@iip.res.in (B.M.S.); \\ adhikari@iip.res.in (D.K.A.) \\ * Correspondence: nagendra@iip.res.in or Satya1008@hotmail.com; Tel.: +91-135-252-5924; \\ Fax: +91-135-266-0203
}

Academic Editor: Robert J. K. Wood

Received: 7 April 2016; Accepted: 15 June 2016; Published: 28 June 2016

\begin{abstract}
The present concept of being globally "green" puts additional demands on lubricants. They are to be biodegradable and ecofriendly. Therefore, in a search for alternate lubricants meeting the above demands, we have synthesized biodegradable new generation esters using alcohols such as 2,2-dimethyl-1,3-propane diol and 2,2-diethyl-1,3-propane diol and fatty acids like caproic and 2-ethyl caproic in presence of indigenous ion exchange resin catalyst. The synthesized esters were analyzed and characterized for their physico chemical properties. In addition, with a view to finding out the possibility of using these esters as aluminum cold rolling oils, their lubricity characteristics, biodegradability and toxicity were also investigated. The products were found to have good potential for use in biodegradable aluminum cold rolling oils meeting IS: 14385-2002 specification.
\end{abstract}

Keywords: new generation esters; renewable; characterization; biodegradable; aluminum cold rolling oil

\section{Introduction}

Increasing environmental awareness and regulations have accelerated the developmental activity of rapid biodegradable lubricants in some parts of the globe in last few years. The new lubricants should not only have good performance but also should be ecofriendly and eventually biodegradable. Esters, poly alkylene glycols, vegetable plant oils and poly alpha olefins are the synthetics dominating the market.

Most of the liquid lubricants used at present all over the world are petroleum based mineral oils. Mineral oil base stocks are derived from crude oil and consist of complex mixtures of naturally occurring hydrocarbons. Synthetic ester lubricants, on the other hand are prepared from manmade base stocks having uniform molecular structures, and therefore well defined properties that can be tailored to specific applications. These esters are another type of synthetic ester made by reacting fatty acids originating from vegetable oils with petrochemical derivatives such as neopentyl glycol and 2,2-diethyl-1,3-propane diol. Lubricants based on synthetic polyol esters are growing in popularity in cold rolling oil applications. Environmentally friendly synthetic polyol esters constitute alternatives to mineral and vegetable oil based cold rolling lubricants. These Synthetic polyol esters are much more flexible in their application usage compared with natural esters because of their much wider viscosity range, higher oxidative and thermal stability and better low temperature flow characteristics with high degree of biodegradability and low aquatic toxicity [1-7].

Rolling is one of the industrial processes which use the plastic behavior of metals for producing shape change. Rolling of aluminum is done both hot and cold. During the hot rolling operation, thick 
cast aluminum slabs are converted into hot plate or strip of desired thickness, which after cooling to room temperature are rolled in a cold mill to produce sheets and foils of required finish gauge. In the case of cold rolling operations, straight run light mineral oils distilled with low viscosity are generally used for sheet rolling and for foil production. Normally, special distillate cuts are used, together with a suitable dosage of film forming additives. In the case of hot rolling, cooling is done by soluble oil emulsion in water, where water acts as a coolant and the oil portion of the emulsion provides lubrication [8]. Conventional cold rolling oils are used to impart lubrication at the roll work piece interface and for cooling of the rolls. Cold rolling oil not only reduces energy consumption but also enhances the roll life resulting in improved product quality [8-11].

An oil/emulsion is introduced at the roll bite in the process of cold rolling to control friction at the interface of the work rolls and strip. Rolling oils must possess appropriate emulsion forming, lubrication and corrosion protection properties and also be easily removed from the strip surface prior to the application of the hot dip metallic coating. Rolling oil must have an appropriate pressure-viscosity coefficient and resistance to thermal degradation, polymerization and hydrolysis. Synthetic di- and tri-ester derivatives of natural vegetable oils are commonly used as the basis of rolling oil formulations [12-14].Numerous different additives, including free fatty acids, emulsifiers and mineral oil together with minor additives such as anti-oxidants, lubrication additives, viscosity boosting agents and corrosion inhibitors are then blended into the base oil to construct fully-formulated cold rolling oil $[15,16]$.

In this paper we present the results carried out on the synthesis, physicochemical characterization and performance evaluation of the neopentyl glycol synthetic polyol esters and the suitability of these esters as base stocks for aluminum cold rolling oils.

\section{Experimental}

\subsection{Materials}

The raw materials caproic, 2-ethyl caproic acids and polyols 2, 2-dimethyl-1, 3-propane diol and 2, 2-diethyl-1, 3-propane diol used for the synthesis were commercial products from Atlas and Godrej (Worli, Mumbai, India). The catalyst was a commercial product from ion exchange India Ltd. (Mahalaxmi, Mumbai, India).

\subsection{Synthesis}

Synthesis of esters with different alcohols, acids and nonconventional ion exchange resin catalyst was done in round bottom flask fitted with a thermometer, a Dean and Stark receiver and a reflux condenser. Depending upon the nature of reactants the contents were refluxed up to $6 \mathrm{~h}$ with a solvent xylene at $138^{\circ} \mathrm{C}$ and then cooled to room temperature, filtered and washed with water. The solvent xylene was recovered under vacuum and the product was passed through a column of activated basic alumina. Under optimized conditions the molar ratio is $1: 1$, reaction temperature is $138^{\circ} \mathrm{C}$, catalyst concentration is $30 \%$ and the yield ranged between $95 \%$ and $96 \%$.

\subsection{Analysis of Synthesized Esters}

The synthesized esters were characterized by FTIR spectroscopy. It was recorded on a Perkin-Elmer IR spectrophotometer in thin film by using KBr pellets.

\subsection{Physico Chemical Properties and Performance Evaluation of Synthesized Ester Lubricants}

The acid value, flash and pour point, kinematic viscosity, viscosity index, color, foaming tendency, copper strip corrosion, Bromine Number, coefficient of friction and antiwear properties of the synthesized esters were determined according to the American Society for Testing and Materials (ASTM) and Bureau of Indian Standards methods. 
The weld load was carried out at $1456 \mathrm{rpm}$ at room temperature. The wear scar diameter was determined under the conditions including the speed of $1200 \pm 60 \mathrm{rpm}$, load of $40 \pm 2 \mathrm{Kgf}$ temperature of $75 \pm 1.7^{\circ} \mathrm{C}$ and test duration of $60 \pm 1 \mathrm{~min}$. by means of the four-ball machine. In this method a steel ball was rotated under the load against three stationary steel balls having surface that was lubricated by oil. After completion of the test, the diameter of the stationary ball was measured to determine the wear preventive characteristic of oil in sliding steel on steel application. Coefficient of friction $(\mu)$ was determined by using ASTM-D-5183-1995 test method.

Ultimate biodegradability characteristics of the synthesized lube base stocks were determined using ASTM-D-5864-95 method. In this, biodegradability is measured by collecting the $\mathrm{CO}_{2}$ produced when the lube oil is exposed to microorganisms under controlled aerobic aquatic conditions. This value then compared to the theoretical amount of $\mathrm{CO}_{2}$ on complete oxidation of the polyol esters [17]. Toxicity of the samples on natural sewage bacteria was determined by the modified method of Algal inhibition test No.L383A/179-185(1993) [18].

\section{Results and Discussion}

\subsection{Literature Report}

In the rolling of aluminum sheets or foils, a lubricant is used to reduce the friction between the rollers and the metal sheet. This ensures good surface finish. In the production of high quality sheets or foils, it is important that any lubricant remaining on the aluminum from the rolling process does not give rise to surface staining or blemish during the subsequent annealing of the aluminum. In the cold rolling of aluminum, desulfurized gas oil or odorless kerosene is often used as the lubricant. However, some manufacturers consider the staining that results from annealing the aluminum in the presence of residual mineral oil based lubricant to be unacceptable, and instead they choose to replace the mineral oil partly or totally with poly urethane. A typical lubricant used for the cold rolling of aluminum might contain 0.5-2 wt\% oleic acid, lauryl alcohol, butyl stearate or palm oil as a lubricity additive and a $\mathrm{Pb}$ with viscosity in the range of $2-4 \mathrm{cSt}$ at $100^{\circ} \mathrm{C}$ [19-21]. In the rolling of aluminum, the need to produce stain free sheets or foils also places certain demands on the lubricants that serve the bearing and hydraulic systems in the mill [22,23].

The available literature showed that some synthetic esters were reported as steel cold rolling oils [24-26]. China patent number CN 102952611A discloses cold rolling oil composition [27]. Steel cold rolling oils are manufactured by the Indian Oil Company (Faridabad, India) with trade names HP Rustop-S, Servo Steerol C4 and C6. HP Rustop, S is most suitable for cold rolled steel components. It can provide rust prevention even in humid and saline atmospheres. Servo Steerol C4 and C6 are premium quality oil in water type emulsifiable fluid, recommended for cold rolling of mild steel and medium carbon steels [28]. Cold rolling oils of Exxcut 225, 1033A, Roll Oil 981 that have also been developed with petroleum base oils, Sulfurized hydrocarbons, fats and esters as the additives, are used to test cold rolling of low carbon steel strips [29]. Another paper on CROs aims at studying the different issues of cold rolling oils, Lubrication measures for improvement in product quality and enhancing mill productivity, and environmental issues.

\subsection{Characterization}

The IR spectrum of all the synthesized esters was shown in Figure 1. According to this spectrum the total esterification was implied by the absence of free-OH stretching frequency around $3650-3590 \mathrm{~cm}^{-1}$ in the IR of all the esters and negligible organic acidity found in all the fluids. The esters carbonyl frequency and the ester carbon-oxygen stretching appeared at $1740 \mathrm{~cm}^{-1}$ and $1180 \mathrm{~cm}^{-1}$ respectively. There were no bands corresponding to $-\mathrm{COOH}$ and $-\mathrm{OH}$ groups indicating the esterification of all the $-\mathrm{CH}_{2} \mathrm{OH}$ groups of alcohols and complete conversion of $-\mathrm{COOH}$ groups. 

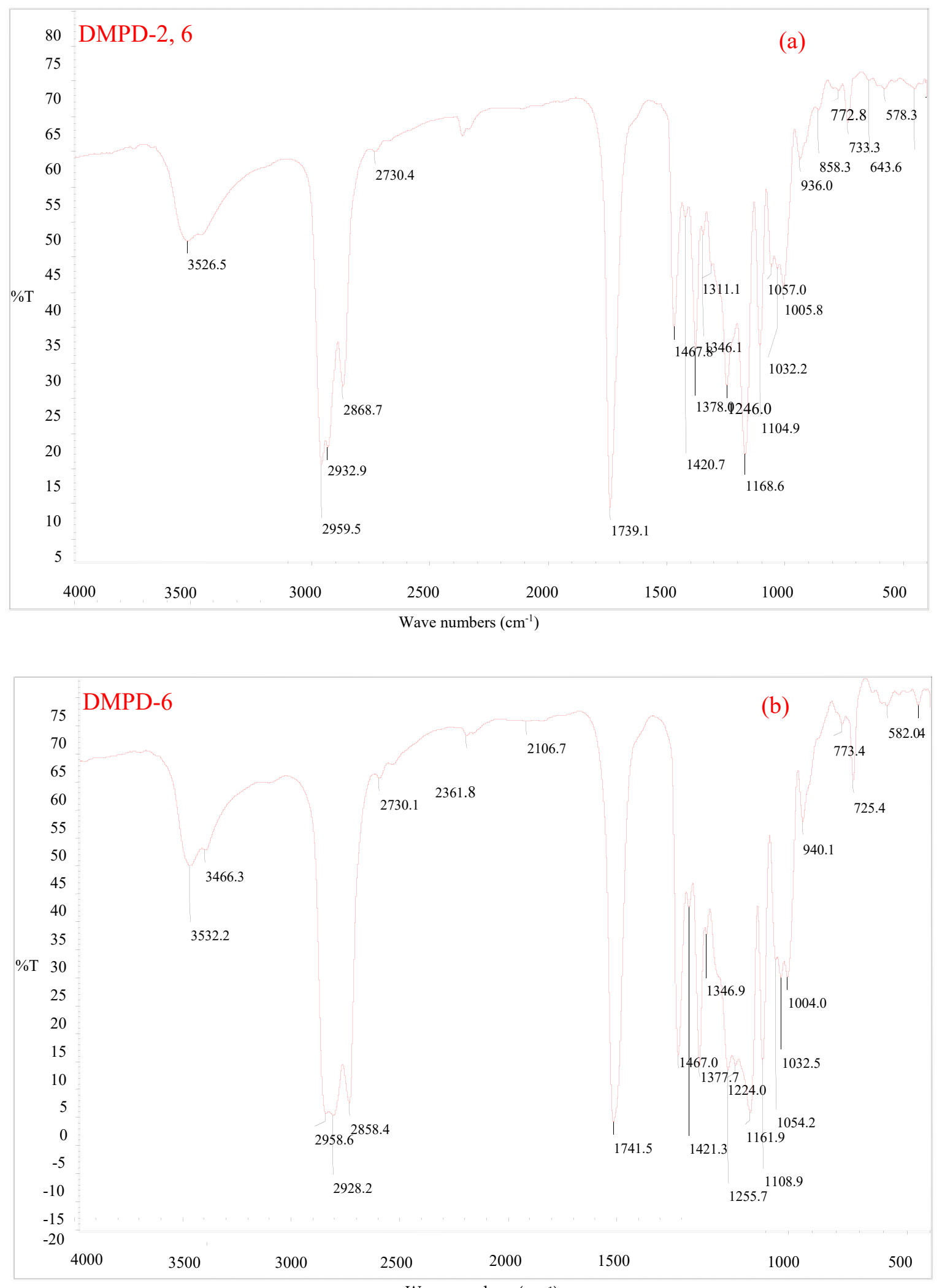

Wave numbers $\left(\mathrm{cm}^{-1}\right)$

Figure 1. Cont. 


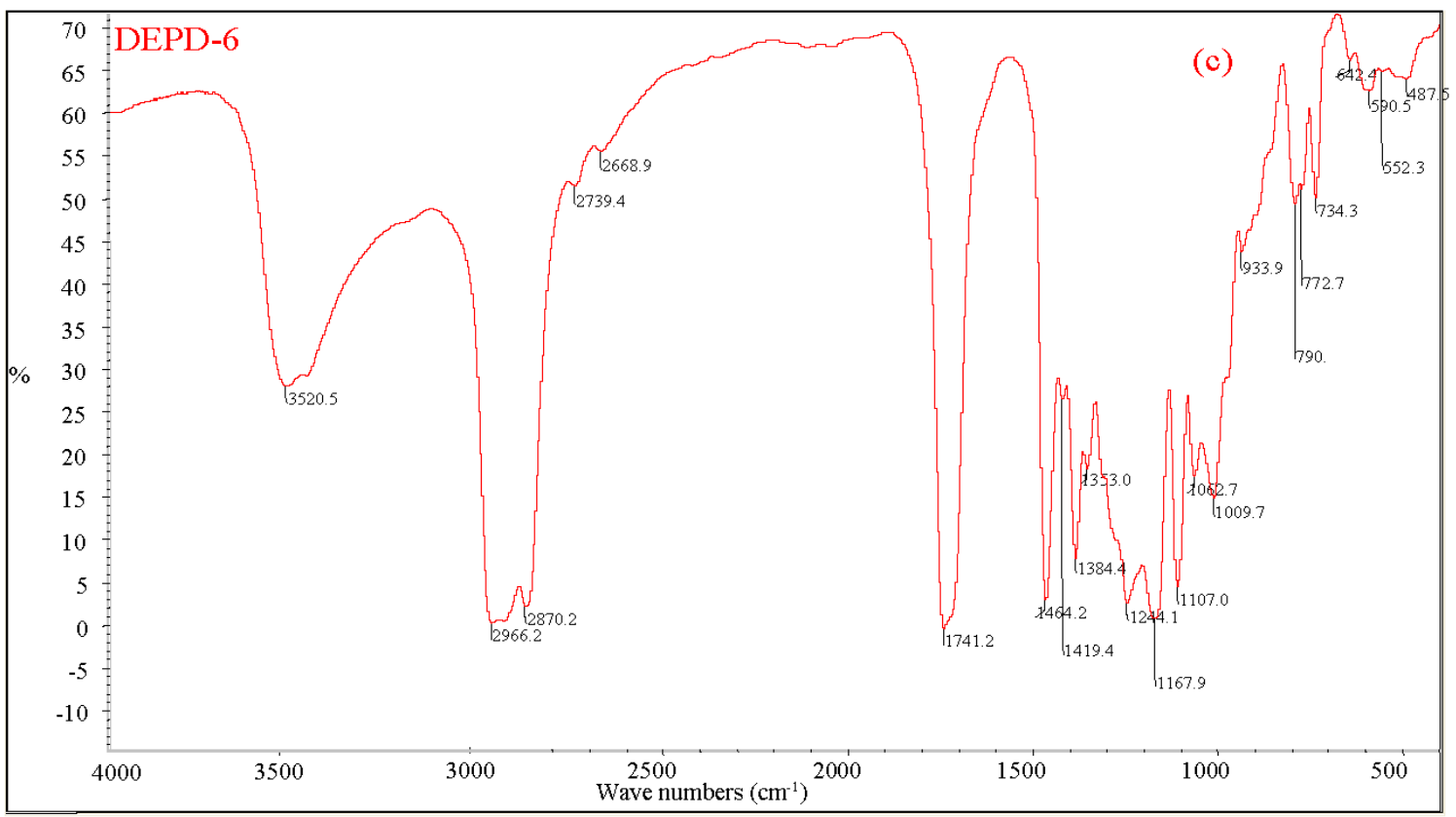

Figure 1. (a-c) Esterification of caproic and 2-ethyl caproic acids with DMPD and DEPD.

\subsection{Physico Chemical Properties}

The physico-chemical properties of these esters are shown in Table 1. The viscosity of the synthesized esters was measured at $40{ }^{\circ} \mathrm{C}$. The prepared esters have viscosities of $4.55-4.98 \mathrm{cSt}$ slightly higher than the specification. Based on the requirement for viscosity, products matched the grade- 2 aluminum cold rolling oils specifications (Table 2). The viscometrics properties of esters are dependent upon the molecular weight of the ester and the degree of branching in the acid. The viscosity of an ester lubricant can be altered by increasing the molecular weight of the molecule, degree of branching in the molecular backbone and maximizing the dipolar interactions. The product DMPD-2,6 has high molecular weight and branch, and higher viscosity.

Table 1. Physico chemical properties of synthesized aluminum cold rolling oils.

\begin{tabular}{|c|c|c|c|c|c|}
\hline \multicolumn{2}{|c|}{ Properties } & DMPD-6 & DMPD-2,6 & DEPD-6 & Method \\
\hline \multicolumn{2}{|c|}{ Viscosity, cSt at $40^{\circ} \mathrm{C}$} & 4.55 & 4.98 & 4.76 & ASTM-D-445/01 \\
\hline \multicolumn{2}{|c|}{ Pour point, ${ }^{\circ} \mathrm{C}$} & -27 & $<-27$ & $<-27$ & ASTM-D-97/96a \\
\hline \multicolumn{2}{|c|}{ Flash point, ${ }^{\circ} \mathrm{C}$} & 154 & 144 & 157 & ASTM-D-92/01 \\
\hline \multicolumn{2}{|c|}{ Density $\mathrm{d}_{4}{ }^{20}, \mathrm{gm} / \mathrm{mL}$} & 0.91 & 0.91 & 0.9271 & ASTM-D-4052 \\
\hline \multicolumn{2}{|c|}{ Acid value, $\mathrm{mg} \mathrm{KOH} / \mathrm{g}$} & 0.03 & 0.03 & 0.03 & ASTM-D-974/01 \\
\hline \multicolumn{2}{|c|}{ Saponificationvalue, mg KOH/gm } & 300 & 356 & 328 & ASTM-D-94/00 \\
\hline \multicolumn{2}{|c|}{ Copper strip corrosion } & $<1$ & $<1$ & $<1$ & IS:1448:P-15 \\
\hline \multicolumn{2}{|c|}{ Noack volatility $250^{\circ} \mathrm{C}$} & 19.3 & 19.7 & 16.8 & DIN-51581 \\
\hline \multirow[t]{3}{*}{ Foaming of } & Seq. I & Nil/Nil & Nil/Nil & Nil/Nil & \multirow{3}{*}{ IS: 1448:P-67:1982 } \\
\hline & Seq. II & Nil/Nil & Nil/Nil & Nil/Nil & \\
\hline & Seq. III & Nil/Nil & Nil/Nil & Nil/Nil & \\
\hline
\end{tabular}


Table 2. Comparison of synthesized ester products with Aluminum cold rolling oils, IS: 14385-2002.

\begin{tabular}{|c|c|c|c|c|c|c|}
\hline Characteristics & Grade I & Grade II & DMPD-6 & DMPD-2,6 & DEPD-6 & Method \\
\hline Color, ASTM, Max & 0.5 & 0.5 & 0.4 & 0.4 & 0.4 & $P: 12$ \\
\hline Kin. Viscosity cSt, at $40^{\circ} \mathrm{C}$ & $1.8-2.9$ & $3.0-4.0$ & 4.55 & 4.98 & 4.76 & $P: 25$ \\
\hline Flash point, $\mathrm{COC},{ }^{\circ} \mathrm{C}$ Min & 115 & 120 & 154 & 144 & 157 & P:69 \\
\hline \multicolumn{7}{|l|}{ Distillation characteristics: } \\
\hline Initial boiling point, (IBP), ${ }^{\circ} \mathrm{C}$, Min & 240 & 275 & NA & NA & NA & $\mathrm{P}: 18$ \\
\hline Final boiling point, $(\mathrm{FBP}),{ }^{\circ} \mathrm{C} \mathrm{Max}$ & 280 & 305 & & & & \\
\hline Acidity Inorganic, mg KOH/g & Nil & Nil & Nil & Nil & Nil & $\mathrm{P}: 2$ \\
\hline Total Acid Number, (TAN) mg KOH/g, Max & 0.02 & 0.03 & 0.03 & 0.03 & 0.03 & ASTM-D-974/01 \\
\hline Total Acid Number, (TAN) mg KOH/g Max, after ageing (at $110 \pm 2{ }^{\circ} \mathrm{C}$ for $48 \mathrm{~h}$ ) & 0.02 & 0.03 & 0.03 & 0.03 & 0.03 & ASTM-D-974/01 \\
\hline Color change after ageing & Unchanged & Unchanged & Unchanged & Unchanged & Unchanged & \\
\hline Sulphur, percent by mass, Max & 0.06 & 0.06 & Nil & Nil & Nil & P:33 \\
\hline Aromatic hydrocarbons, percent by volume, Max & 30 & 30 & Nil & Nil & Nil & $\mathrm{P}: 23$ \\
\hline Bromine No. by Electrometric titration, Max & 1 & 1 & Nil & Nil & Nil & \\
\hline Ultraviolet (UV) absorbency, Max, at wave length in mill micron & & NA & NA & NA & NA & \\
\hline Water content (Crackle Test) & Negative & Negative & Negative & Negative & Negative & \\
\hline
\end{tabular}


Low pour point $\left(-27^{\circ} \mathrm{C}\right)$ of these esters will improve the efficiency and increase the life of components subject to wear. The flash point $\left(144-157^{\circ} \mathrm{C}\right)$ of these esters showed that they have superior flash point properties against the specification which is desirable from safety point of view, resulting in a much better fire resistant property. The acidity was found to be nil. The Saponification value (300-356) of synthesized esters is very high and gives an added advantage for improving their lubricity performance.

\subsection{EP \& Wear Properties}

Although no performance tests are laid down in the specification (IS: 14385-2002) for aluminum cold rolling oils, we have evaluated all the esters for their EP and wear behavior. The tribological properties are given in Figure 2 which is quite comparable with and even better than commercial base oils (Table 2). The cold rolling oils should have moderate to high load bearing capacity and good lubricity property. The load bearing capacity is determined on a 4-ball E.P. tester. Table 3 shows the performance data obtained with commercial rolling oils. As a general rule, esters prepared by normal acid or alcohols have better lubricities than those made from branched acids/alcohols, while esters made from mixed acids/alcohols have lubricities intermediate between esters of normal acids/alcohols and esters of branched acids/alcohols.

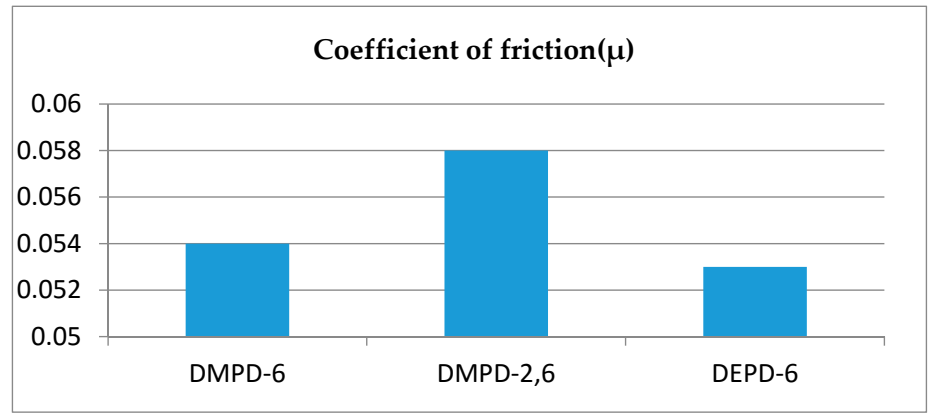

(a)

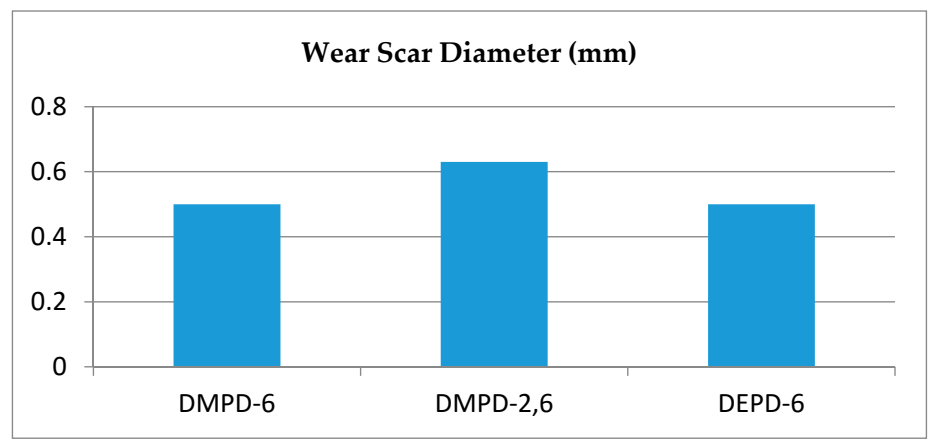

(b)

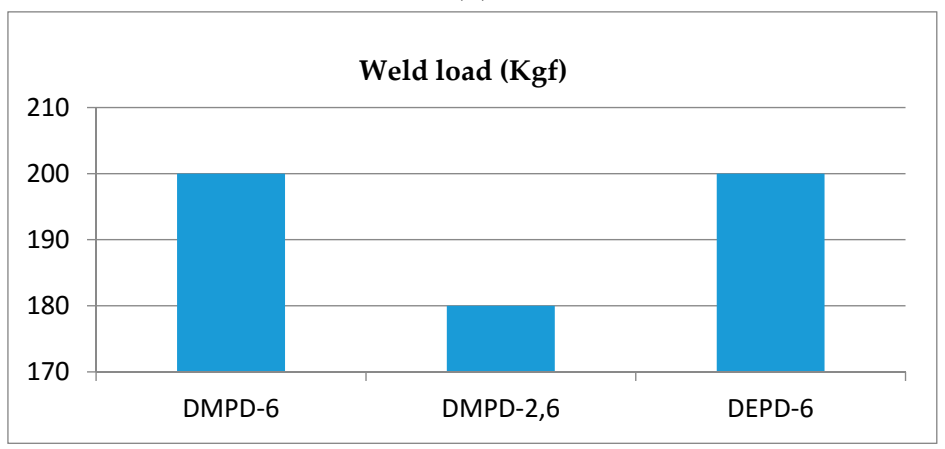

(c)

Figure 2. (a-c) Performance evaluation of synthesized aluminum cold rolling oils. 
Table 3. Performance of commercial rolling oils.

\begin{tabular}{cccc}
\hline Synthesized Ester Samples & Commercial Cold Rolling Oil & Coefficient of Friction $(\mu)$ & Weld Load (Kgf) \\
\hline- & CRO1 & 0.081 & $160(1568 \mathrm{~N})$. \\
- & CRO2 & 0.096 & $140(1372 \mathrm{~N})$. \\
DMPD-6 & - & 0.054 & $200(1961 \mathrm{~N})$. \\
DMPD-2,6 & - & 0.058 & $180(1765 \mathrm{~N})$. \\
DEPD-6 & - & 0.053 & $200(1961 \mathrm{~N})$. \\
\hline
\end{tabular}

From Figure 2c it can be observed that the load bearing capacity performance (weld load) of polyol esters ranges from 180 to $200 \mathrm{Kgf}(1765-1961 \mathrm{~N})$. These values are comparable to those of commercial CROS in Table 3. The polyol ester DMPD 6 and DEPD 6 shows the best performance with respect to load bearing capacity. The wear scar diameter of the synthesized ester samples was between 0.500 and 0.630. The samples DMPD 6 and DEPD 6 shows better wear scar diameter Figure $2 b$ than DMPD-2, 6 . The results of lubricity test Figure 2a shows that the coefficient of friction lies between 0.053 and 0.058 . The coefficient of friction is least for ester DEPD-6.The esters have comparable frictional characteristics with those of commercial CROS (Table 3). The friction between tool and work piece must be neither too high nor too low. Overall, it can be seen from the tribological performance data that the synthesized esters have comparable performances to that of commercial CROs.

\subsection{Comparison of Polyol Lube Base Stocks with BIS Specification (IS: 14385-2002)}

The lower pour point together with better load bearing capacity shows that polyol esters can be used as potential lube base stocks. A comparison of synthesized polyol lube base stocks with BIS specifications of (IS: 14385-2002) for aluminum cold rolling oil specifications are given in Table 2 . From the table it is evident that the polyol esters are comparable with the grade II (Intended for heavy rolling) oils. The products were showed negligible inorganic and organic acidity. Aromatic hydrocarbons and sulphur percent were not present in the synthesized samples. The bromine number is a measure of the amount of carbon-carbon double bond unsaturation per unit weight of material. Polyols contain no double bonds hence they were not showed any unsaturation. Bromine number by electrometric titration is found to be nil. The ultraviolet (UV) absorbency testis only for mineral oil based rolling oils. The color of the samples is unchanged after ageing. Another important feature of these chemically derived base fluids is their biodegradability characteristics, which is in the range of $95 \%-98 \%$. The samples were also nontoxic to the sewage bacteria.

Finally, when we compared our aluminum cold rolling oils with commercially available CRO in Table 2, we found that the properties are better than those of commercial oil.

Generally low viscosity lubricating oils are used in manufacturing of cold rolling oils because of their better cooling and penetration properties. Esters, due to their polarity, adhere more closely to the metal surface and provide strong film strength. These esters do not congeal at low temperature because of high viscosity index. Esters show good viscosity volatility relationship and have considerably lower viscosity than mineral oils at given temperatures and low volatility at high temperatures.

The synthesized polyol esters have high viscosity index and flash point with negligible organic acidity being satisfactory with lubricity and oxidative stability. The esters also exhibit excellent biodegradability and nontoxicity without any additive package.

\section{Conclusions}

The polyol esters of polyol $\left(C_{5}\right)$ and monocarboxylic acids $\left(C_{6}-C_{8}\right)$ were synthesized. The esters are biodegradable and have excellent physico-chemical characteristics. They exhibit good tribological properties.

The limited studies indicate that polyol esters have a good potential for use as base stock for grade I aluminum cold rolling oils of IS: 14385-2002, intended for sheet rolling and for foil production.

Grade 1: Intended for light rolling. Grade II: Intended for heavy rolling.

Further studies are needed for the development of final rolling oil formulations. 
Acknowledgments: The authors are grateful to acknowledge the support \& facilities extended by Director, IIP and Council of Scientific and Industrial Research, India for funding. We would also like to express sincere thanks to, Director, CSIR-IIP for encouragement and support in carrying out this work and granting permission to submit paper for publication in the journal "Lubricants".

Author Contributions: The contribution of the first author Ponnekanti Nagendramma includes collection of data by performing the experiments and interpretation of the collected data and writing of the manuscript. The contribution of the second author includes tribological performance and third author includes biodegradability and toxicity studies. The design and plan of the experiments was carried out by both second and third authors.

Conflicts of Interest: The authors have declared no conflict of interest.

\section{Abbreviations}

The following abbreviations are used in this manuscript:

$\begin{array}{ll}\text { IR } & \text { Infra Red } \\ \text { EP } & \text { Extreme Pressure } \\ \text { IS } & \text { ndian Standards } \\ \text { KBr } & \text { Potassium bromide } \\ \text { IP } & \text { Indian Petroleum } \\ \text { rpm } & \text { Revolution per minute } \\ \text { ASTM } & \text { American Society for Testing and Materials } \\ \text { Max } & \text { Maximum } \\ \text { Min } & \text { Minimum } \\ \text { DMPD } & \text { 2,2-dimethyl-1,3-propane diol } \\ \text { DEPD } & \text { 2,2-diethyl-1,3-propane diol, 6-caproic acid and 2,6-2-ethyl caproic acid } \\ \text { CRO } & \text { cold rolling oil }\end{array}$

\section{References}

1. Bioser, E.R. CRC Handbook of Lubrication and Tribology; CRC Press: Bocaraton, FL, USA, 1994; Volume 3.

2. Gunderson, R.C.; Hart, A.W. Synthetic Lubricants; Reinhold Publishing Corp.: New York, NY, USA, 1962.

3. Ponnekanti, N.; Savita, K. Development of ecofriendly/biodegradable lubricants: An overview. Renew. Sust. Energ. Rev. 2012, 16, 764-774.

4. Anand, S.; War, N.; Chaudhari, S.; Chaudhari, P. A study of lubrication and its effect on steel in cold rolling mill: A review. VSRD Int. J. Mech. Civ. Automob. Prod. Eng. 2013, 3, 87-92.

5. Chang, T.-S.; Yunus, R.; Rashid, U.; Choong, T.S.Y.; Awang Biak, D.R.; Syam, A.M. Palm oil derived trimethylolpropane triesters synthetic lubricants and usage in industrial metal working fluid. J. Oleo Sci. 2015, 64, 143-151. [CrossRef] [PubMed]

6. Li, W.; Wang, X. Biolubricants derived from waste cooking oil with improved oxidation stability and low temperature properties. J. Oleo Sci. 2015, 64, 367-374. [CrossRef] [PubMed]

7. Salimon, J.; Salih, N.; Yousif, E. Synthesis, characterization and physicochemical properties of oleic acid ether derivatives as biolubricants base stocks. J. Oleo Sci. 2011, 60, 613-618. [CrossRef] [PubMed]

8. Bureau of Indian Standards. Aluminium Cold Rolling Oils Specification; IS 14385; Bureau of Indian Standards: New Delhi, India, 1996; (Reaffirmed 2002).

9. Jain, V.K. Evaluation of steel cold rolling oil by disc machine. In Proceedings of the Proceeding National Conference on Industrial Tribology, Bombay, India, 6-8 December 1976.

10. Heinrich, H.; Duee, D. IP Handbook; Institute of Petroleum: London, UK, 2000.

11. Bio-Aluminum Cutting Oil (Food Grade) Stabilized Renewable Lubricants. Available online: http://www. renewablelube.com (accessed on 9 February 2016).

12. Shamaiengar, M. Cold Rolling Lubrication Technology. Iron Steel Engineer 1967, 44, 135-141.

13. Gamlin, C.D.; Dutta, N.K.; Chaudhari, N.R.; Kehoe, D.; Matisons, J. Evaluation of kinetic parameters of thermal and oxidative decomposition of base oils by conventional, isothermal and modulated TGA, and pressure DSC. Thermochim. Acta 2002, 357, 392-393. [CrossRef]

14. Fox, N.J.; Stachowiak, G.W. Boundary lubrication properties of oxidized sunflower oil. Lubr. Eng. 2003, $59,15$.

15. Svedung, D.H. The analytical control of cold rolling emulsions. Scand. J. Metall. 1980, 9, 183-187. 
16. Title 21-Food and Drugs; Chapter 1-Food and Drugs Administration, Department of Health and Human Services. Part 178-Indirect Food Additives: Adjutants, Production Aids, and Sanitizers; Sec; 178.3620 Mineral oil. CITE: 21CFR178.3620, Revised as of April 1. US Food and Drug Administration: Silver Spring, MD, USA, 2013; Volume 3.

17. ASTM-D-5864-95. In Standard Test Method for Determining Aerobic Aquatic Biodegradation of Lubricants or Their Components; American National Standards Institute: New York, NY, USA, 1996.

18. Van Miert, K. Methods for the determination of ecotoxicity, C3-Algal inhibition test. Off. J. Eur. Communities 1993, 383A, 179-185.

19. Plemich, J.J. Non-staining aluminum rolling lubricant. US patent 2899390 to standard oil, 11 August 1959.

20. Baur, R. Lubricant for metal strip. US patent 4228217, to Swiss Aluminium Ltd., 6 September 1977.

21. Baur, R. Hydraulic fluid. US patent 4488979, to Swiss Aluminium Ltd., 23 February 1982.

22. Rudnick, L.R. Polybutenes, J.D., Fotheringham, B.P., Eds.; Synthetics, Mineral Oils, and Bio-Based Lubricants: Chemistry and Technology; pp. 274-300. Singapore Pvt. Ltd.: Singapore; CRC Press: Taylor \& Francis Group: New York, NY, USA, 2013.

23. Mortier, R.M.; Orszulik, S.T. Chemistry and Technology of Lubricants; Blackie Academic and Professional Imprint of Chapman and Hall: London, UK, 1997.

24. Mahanti, S.; Bhatta, A.K.; Biswas, R.N.; Bhatia, J.; Singh, S.N. Development of a meta-stable semi-synthetic lubricant for cold rolling of steel. J. Synth. Lubr. 1990, 6, 285-298. [CrossRef]

25. Gaillard, X.; Mascaro, A. Synthetic esters: New applications for steel cold rolling. In Presented in the European Steel: Cold Rolling Mill Conference, Germany, 1 April 1993.

26. Okabe, H.; Kanno, T. Behaviour of polar compounds in lubricating oil films. ASLE Trans. 1981, 24, 459-466. [CrossRef]

27. Guo, H.; Liu, K. Rolling Oil Composition for Cold-Rolled Sheet. CN Patent 102952611A, 16 March 2013.

28. Indian Oil, Servo Product Data Sheet. Available online: http://www.ioml.mu/mirror/download/SpecialityGrades.pdf (accessed on 9 December 2015).

29. McConnell, C.; Lenard, J.G. Friction in cold rolling of low carbon steel with lubricants. J. Mater. Process. Technol. 2000, 99, 86-93. [CrossRef]

(c) 2016 by the authors; licensee MDPI, Basel, Switzerland. This article is an open access article distributed under the terms and conditions of the Creative Commons Attribution (CC-BY) license (http://creativecommons.org/licenses/by/4.0/). 